\title{
Delamination toughness of ultra high molecular weight polyethylene (UHMWPE) composites
}

\author{
A. Porras, J. Tellez, and J.P. Casas-Rodriguez \\ Universidad de los Andes, Mechanical Engineering Department, Bogota, Colombia
}

\begin{abstract}
Ultra high molecular weight polyethylene (UHMWPE) fibre reinforced composites are an important group of material for armours solutions, where their unique combination of properties could be utilized. A commonly observed failure mode in this kind of unidirectional laminated composites under impact ballistic is delamination between the composite layers. In the present study, an investigation on the delamination toughness behaviour exhibited by UHMWPE composites laminated was made. The interlaminar Mode II critical strain energy release rates of (UHMWPE) fibre reinforced composites were characterized using the End Notch Flexural (ENF) test. Critical strain energy release rate was obtained from the load - deflection test data using the beam theory expression. It was found that the energy release rate of the composite exhibited a very low value of around $60 \mathrm{~J} / \mathrm{m}^{2}$ using a moulding pressure of approximately $1200 \mathrm{psi}$. In order to analyse the delamination resistance of composite, the effects of changing the manufacture process variables and the use of a thermoplastic adhesive film in the composites were investigated. The composite laminates were produced by hot compressing moulding using a film-stacking procedure. It was found that the damage resistance of the UHMWPE composite was influenced by the manufacture method, which affects the Mode II interlaminar fracture toughness and the ballistic response of composites.
\end{abstract}

\section{Introduction}

Lightweight ballistic protection armour systems are currently made using composite materials, due to its good protection/weight relation. Specifically, polymeric composite materials have been largely used worldwide in ballistic protection materials as soft or hard armour, due to their very good impact energy absorbing capacity. These composites are generally constructed using high-modulus/highstrength polymeric fibres [1].

Ultrahigh molecular weight polyethylene (UHMWPE) fibre has been considered, by some researchers, as one of the strongest and lightest material. It has unique properties including chemical resistance, low density, high strength, and high toughness. Also, UHMWPE shows a great potential as lightweight material for armour solution, due their extraordinary capability of absorbing the kinetic energy of projectiles. For these reasons, many studies have attempted to apply UHMWPE as reinforcement for several products. In fact, UHMWPE composites has been used in the production of armour materials for personnel protection (vests and helmets), and in military and civil armoured vehicles nowadays $[2,3]$.

One of the most common experimentally observed failure mode in fibre reinforced composite armours is delamination, a separation of the fibre reinforced layers that are stacked together to form laminates. Delamination occurs mainly due to high interlaminar stresses developed at the bonding interface between layers of dissimilar orientation and/or materials [4]. The delamination failure modes are usually classified into three basic modes: opening mode (mode I), sliding shear mode (mode II), and scissoring shear mode (mode III); also, mixed-mode delamination occur according to the predominant stresses acting on the interface. For example, pure mode I delamination is exclusively due to the through-thickness tensile normal stress which leads to layer debonding in the direction normal to the interface. Mode II and III refers to the out of-plane shear stresses which results in relative sliding between upper and lower layers. Mixed-mode delamination is a combination of modes I, II and III. [5,6]

On the other hand, the analysis of the ballistic response of armour when impacted with high speed projectiles has been studied for several authors. In his work, Grujici [7] studied projectile/armour interaction for $0^{\circ} / 90^{\circ}$ cross-plied UHMWPE-based- armour-grade composite. Their experiment and the computational analysis predict that initial penetration of the armour panel is first dominated by filament shearing/cutting and subsequently by filament/matrix debonding/delamination. That is, under transverse impact, the projectile pushes a strip of the first lamina toward the rear of the laminate which induces shear cracks in the resin matrix parallel to the fibres and applies a transverse load to the second lamina. This, in turn, causes separation between the first two laminates, i.e. delamination. After the successive delamination had taken place through the entire thickness of the laminate via the same mechanism and penetration of the laminate has occurred, narrow strips of damage zone remain visible under the transmitted light and the strips are found to follow the respective fibre orientation in the panel. These strips typically contain numerous matrix/fibre interface cracks. In addition, a circular delamination zone is generally seen around the perforation hole.

In this context, delamination is an important failure mechanism of UHMWPW composites. In addition, the study of factors as composite processing and fabrication conditions become important, for full utilization of this potential in armour-grade composites. Therefore, the aim of this work was to investigate the delamination toughness behaviour exhibited by UHMWPE composites laminated. The effects of changing the manufacture process variables and the use of a thermoplastic adhesive film in the composites were evaluated. The interlaminar Mode II 
Table 1. Manufactured panel conditions.

\begin{tabular}{|l|c|c|c|}
\hline $\begin{array}{l}\text { Panel } \\
\text { Number }\end{array}$ & $\begin{array}{c}\text { Molding } \\
\text { Pressure (Psi) }\end{array}$ & $\begin{array}{c}\text { Adhesive } \\
\text { film }\end{array}$ & Preformed \\
\hline 1 & 1200 & No & No \\
\hline 2 & 300 & No & No \\
\hline 3 & 1200 & Yes & No \\
\hline 4 & 300 & Yes & No \\
\hline 5 & 300 & Yes & Yes \\
\hline
\end{tabular}

critical strain energy release rates of (UHMWPE) fibre reinforced composites were characterized using the End Notch Flexural (ENF) test; and microscopic techniques were used to deduce the damage growth mechanisms.

\section{Experimental}

\subsection{Materials}

Ultra high molecular weight polyethylene fibre reinforced composite laminate (UHMWPE) was used for this work. Every lamina is constructed with UHMWPE fibres layered in a criss-cross $\left(0 / 90^{\circ}\right)$ orientation; therefore, the elastic modulus of the lamina is the same in the $\mathrm{x}$ and $\mathrm{y}$ directions $(\mathrm{Ex}=\mathrm{Ey})$. Different specimens were tested and manufactured using a thermoplastic adhesive film recommended by the manufacturer.

\subsection{Composite preparation}

Composite panels were produced by hot compressing moulding using Laboratory Hydraulic press model LPS-80 (Labtech Engineering Co., Ltd.) by film-stacking procedure. Composites were moulded at $130^{\circ} \mathrm{C}$ for a total pressing time around of $30 \mathrm{~min}$.

In order to evaluate the effects of both, changing the moulding pressure (Low/High) and the use of a thermoplastic adhesive film (adhesive in the middle of the panel) in the composite processing, five different panels were manufactured under the conditions shows in the table 1.

Figure 1 shows how panels were organized in hot compressing moulding process. To simulate a mid-plane delamination taken place in the composite panel, a thin a thin aluminium film was inserted between 10th and 11 th laminate layer during the fabrication process. Then, a rectangular ENF specimen was shaped from the composite panel.

Panel number five was manufactured in a different way. First, two different panels of 10 sheets each one, were preformed on their own $\left(1200 \mathrm{psi}, 130^{\circ} \mathrm{C}\right.$, no crack, no adhesive). After this process they were compressed together using the adhesive film $\left(300 \mathrm{psi}, 130^{\circ} \mathrm{C}\right.$, crack, adhesive).

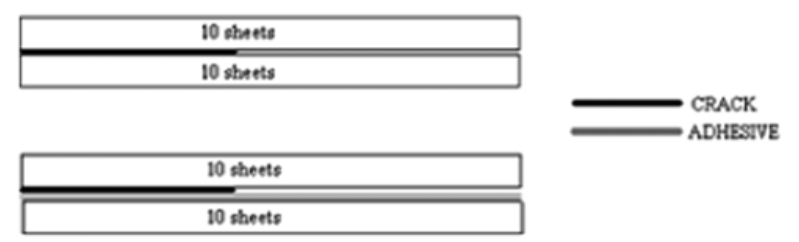

Fig. 1. Panels structure with and without adhesive film.

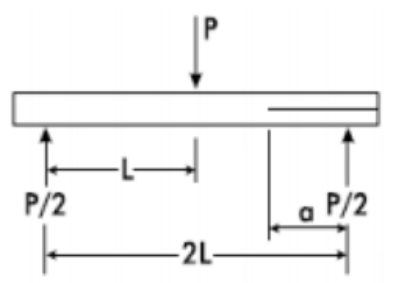

Fig. 2. ENF test. Specimen geometry parameter in.

\section{ENF test}

In order to evaluate the delamination failure mode in UHMWPE composite panels, the End-Notched Flexure (ENF) test was performed. End notched flexure test purpose is to determine critical strain energy release rate $\left(G_{I I}\right)$ by loading the specimen in pure mode II (shearing). The procedure consists in a three point bending test which follows basic beam theory. Each specimen is loaded in bending as shown in the figure 2 .

The energy release rate, $G_{I I}$, was calculated from the following beam theory expression (1)

$$
G_{I I}=\frac{9 a^{2} P_{\max }^{2}}{16 w^{2} h^{2} E_{1}}\left[1+0.2\left(\frac{h}{a}\right)^{2} \frac{E_{1}}{G_{13}}\right]
$$

where $P$ is the maximum load applied, $a$ is the crack length, $w$ is the specimen width, $h$ is half of the specimen thickness, $E_{1}$ is young's modulus of the material and $G_{13}$ is the shear modulus for the material out of plane.

All End-Notched-Flexure tests were performed on Instron tester machine model 3367, using a distance between supports of $100 \mathrm{~mm}$ and a crosshead speed of $1 \mathrm{~mm} / \mathrm{min}$. Specimen dimensions of each panel is described in the table 1. The initial crack length was around of $25 \mathrm{~mm}$. Before the test all specimens were set up in the laboratory at $25^{\circ} \mathrm{C}$ and $49 \%$ relative humidity during 24 hours. Five specimens of each panel were tested to obtain average strain energy release rates. After the test, specimens were observed in stereoscope Olympus SZX9, in order to analyze the damage growth mechanisms.

\section{Results and discussion}

The characteristic load - displacement curves for a specimen of each UHMWPE composite panels are shown in the figure 3. The response curves were similar for all the composite panels, although the critical load for crack propagation was different for each case and the energy release rate too (figure 4). This response is commonly 
Table 2. Specimen dimensions of each panel.

\begin{tabular}{|l|c|c|}
\hline Panel Number & Wide $[\mathrm{mm}]$ & Thickness $[\mathrm{mm}]$ \\
\hline 1 & $24.64 \pm 0.61$ & $4.87 \pm 0.005$ \\
\hline 2 & $24.31 \pm 0.44$ & $5.08 \pm 0.01$ \\
\hline 3 & $24.30 \pm 0.56$ & $4.95 \pm 0.02$ \\
\hline 4 & $24.80 \pm 0.41$ & $5.06 \pm 0.03$ \\
\hline 5 & $24.68 \pm 0.93$ & $4.61 \pm 1.34$ \\
\hline
\end{tabular}

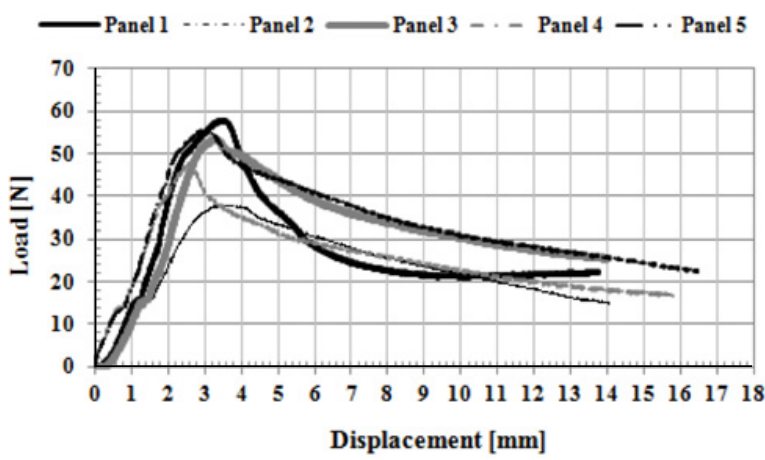

Fig. 3. Load vs displacement curves for composite panels.

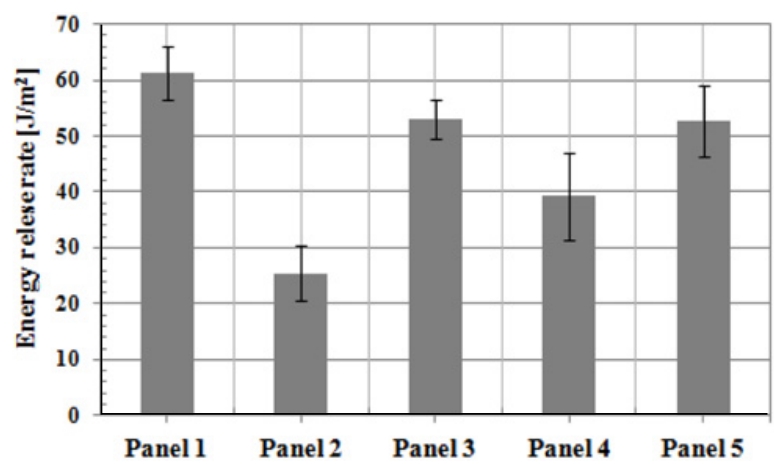

Fig. 4. Energy release rate for each composite panel.

observed in ductile matrix composites, a non-linear elastic mechanical behaviour, with slow crack propagation.

The macroscopic observation of the fractured ENF specimens is photographically illustrated in figure 5. As can be seen, all UHMWPE composite panels showed the crack propagation, however the damage growth mechanisms was different and depend of manufacture process.

According to the experimental test, an improvement in energy release rate was found when higher pressure mould was used. For example, panel 1 and panel 2 were manufactured at $1200 \mathrm{psi}$ and $300 \mathrm{psi}$, respectively, and as can be seen from figure 4, the average value of energy release rate $G_{I I}$ in panel $1\left(61.32 \pm 4.90 \mathrm{~J} / \mathrm{m}^{2}\right)$ was greater than panel $2\left(25.47 \pm 4.92 \mathrm{~J} / \mathrm{m}^{2}\right)$.

On the other hand, a common occurrence in testing unidirectional specimens is fibre bridging, which refers to the debonded fibres the fracture surface. As illustrated in figure 6 , this behaviour was observed in panel 1 manufactured at high pressure, in spite of the panel 2, that no

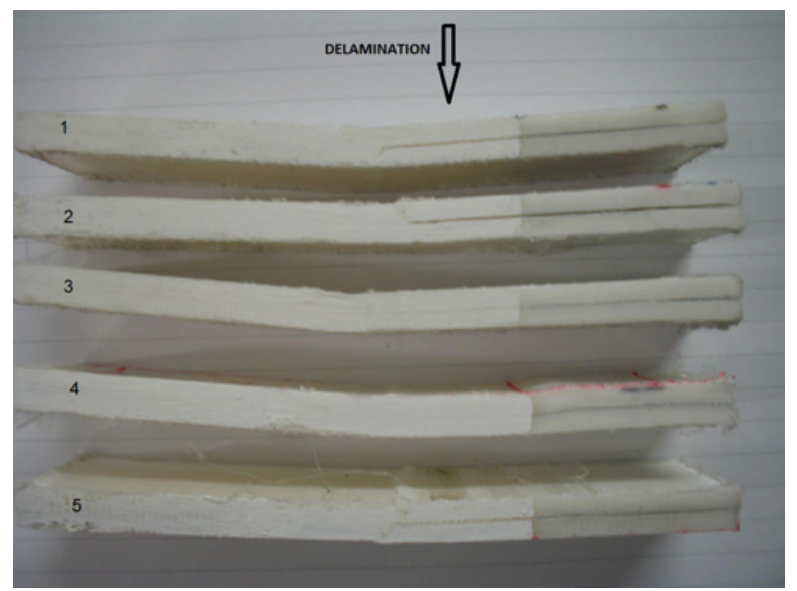

Fig. 5. ENF specimens after the test.

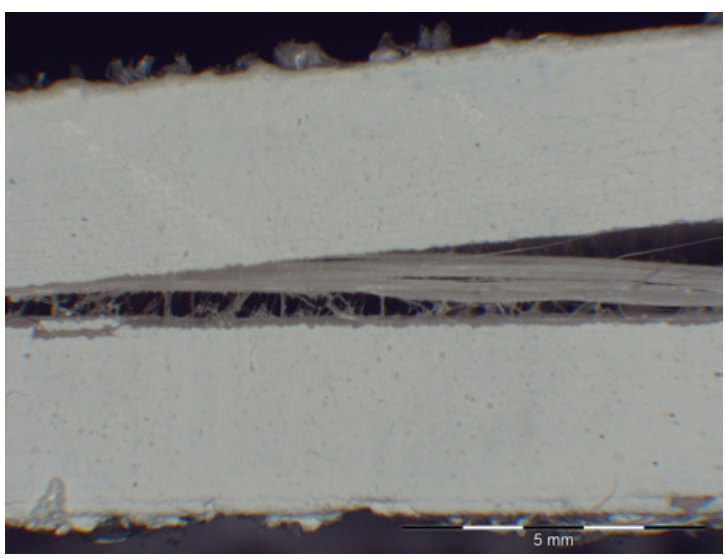

Fig. 6. Panel 1: fiber bridging effect.

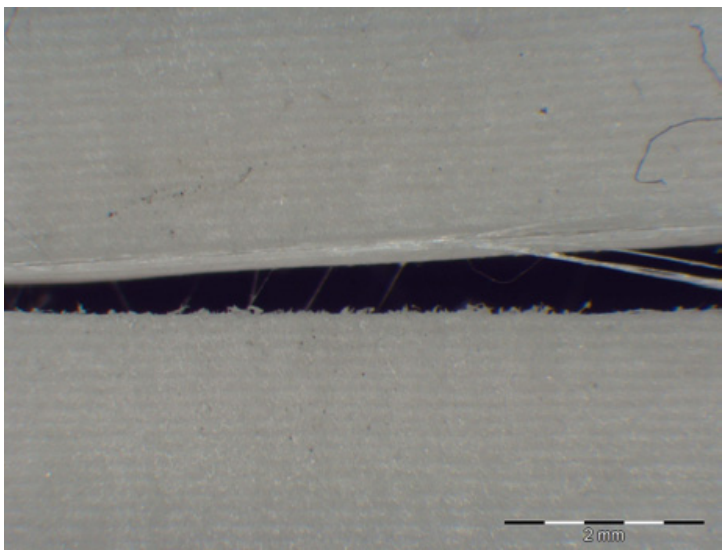

Fig. 7. Panel 3.

bridges present, as can be seen in figure 7 . It is important to take account that, the fibre bridging elevates the fracture resistance as a result of the closure tractions that develop in the fibre that bridge the crack faces behind the crack tip, and the energy consumed as the bridged fibres deboned from the matrix.

In addition, when the moulding process was made at low pressure with the adhesive film in the mid-plane of the composite (Panel 4) an improvement of $G_{I I}$ was found, as compared with the panel processed at low pressure 


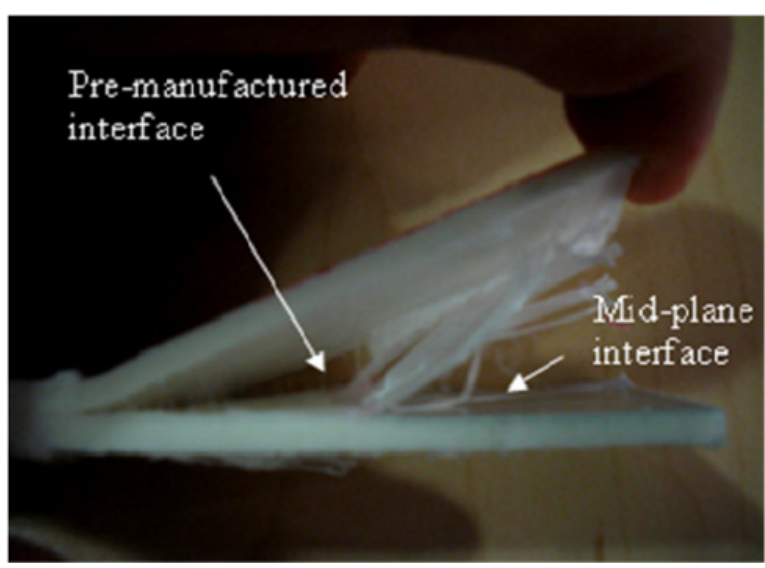

Fig. 8. Crack propagation under pre-manufactured interface.

(Panel 2). The energy release rate for panel 4 was about $54.56 \%$ better compared to Panel 2. Nevertheless, no one increase was found when high pressure mould was used (Panel 3). These results indicate that if the moulding process has been performed with a low capacity pressing machine, the use of the adhesive film should increase the delamination behaviour of the composite.

Additionally, it was found that when adhesive film is incorporated in the mid-plane of the composite panel, the damage growth mechanism was different. The grow crack propagation was done in the pre-manufactured interface by the supplier, instead of mid-plane interface layer. This effect is illustrated in the figure 8 . Weak interface bond interlayer, promoting interface debonding and subsequent delamination by pre-manufactured interface. It could be enhance increasing the moulding pressure up to $4350 \mathrm{psi}$.

The preformed composite panel (panel 5) presented properties as good as the panel produced at high pressure with adhesive film (panel 3), and comparable with the panel 1. Therefore, if the moulding of composite has been performed at high pressure, they can be joined each other using a film adhesive at low moulding pressure. It is an advantage for application where it is only necessary to join structures.

In summary, depend on the manufacture process condition the fracture toughness behaviour is affected. In general, it was shown that UHMWPE composite display low energy release rate value $G_{I I}$, as compared with other composite panel like carbon/epoxy composites $\left(553 \mathrm{~J} / \mathrm{m}^{2}\right)$ [8], carbon fibre epoxy with Kevlar reinforced interleaves $\left(900-2000 \mathrm{~J} / \mathrm{m}^{2}\right)$ [9] each others. The next challenge in the research is evaluate the fracture toughness behaviour in UHMWPE composites manufactured with at least 2400 psi and up to 4350 psi pressure.

\section{Conclusions}

The effects of changing the manufacture process variables and the use of a thermoplastic adhesive film in the
UHMWPE composites were evaluated by ENF test. An improvement in energy release rate was found when both higher pressure mould and low pressure with adhesive film in the mid-plane of the composite were used. Also, in some cases it was found that fibre above and below the mid-plane tend to bridge the delamination. Additionally, when adhesive film was incorporated in the composite, the grow crack propagation was done in the pre-manufactured interface by the suppliers, instead of mid-plane interface layer. Finally, preformed composite can be joined each other using a film adhesive at low moulding pressure, an advantage for application where it is only necessary to join structures.

\section{Acknowledgements}

Authors are grateful to both military industry (INDUMIL) of Colombia and the Structural Integrity group (GIE) of mechanical engineering department.

\section{References}

1. David, N., X.L. Gao, and J. Zheng, Ballistic Resistant Body Armor: Contemporary and Prospective Materials and Related Protection Mechanisms. Applied Mechanics Reviews, 2009. 62: p. 050802.

2. dos Santos Alves, A.L., L.F. Cassiano Nascimento, and J.C.M. Suarez, Influence of weathering and gamma irradiation on the mechanical and ballistic behavior of UHMWPE composite armor. Polymer testing, 2005. 24(1): p. 104-113.

3. Lin, S., et al., Composites of UHMWPE fiber reinforced PU/epoxy grafted interpenetrating polymer networks. European Polymer Journal, 2007. 43(3): p. 996-1008.

4. Kim, J. and Y. Mai, Engineered interfaces in fiber reinforced composites. 1998: Elsevier Science Ltd.

5. Bürger, D., et al., Ballistic impact simulation of an armour-piercing projectile on hybrid ceramic/fiber reinforced composite armours. 2011.

6. Daniel, I., O. Ishai, and I. Daniel, Engineering mechanics of composite materials. 1994: Oxford University Press New York.

7. Grujicic, M., et al., A ballistic material model for cross-plied unidirectional ultra-high molecularweight polyethylene fiber-reinforced armor-grade composites. Materials Science and Engineering: A, 2008. 498(1-2): p. 231-241.

8. Adams, D.F., L.A. Carlsson, and R.B. Pipes, Experimental characterization of advanced composite materials. 2003: CRC Press Boca Raton, FL.

9. Yadav, S., V. Kumar, and S.K. Verma, Fracture toughness behaviour of carbon fibre epoxy composite with Kevlar reinforced interleave. Materials Science and Engineering: B, 2006. 132(1-2): p. 108-112. 